\author{
(활성탄/고분자바인더)복합성형체의 압출온도에 따르는 응집구조 및 유량 \\ 상관성에 관한 연구 \\ 임용균 $* * *$. 김영준* $\cdot$ 박상진 ${ }^{* *} \cdot$ 홍성규 ${ }^{* * \dagger}$ \\ *(주)마이크로필터 소재개발팀 \\ 365-842 충북 진천군 덕산면 산수리 162-1 \\ **동국대학교 화공생물공학과 \\ 100-715 서울시 중구 필동 3 가 26번지
}

(2013년 10월 11일 접수, 2013년 12월 23일 수정본 접수, 2013년 12월 29일 채택)

\title{
Study on the Relationship between Aggregation Structure and Flow Rate Depending on Extrusion Temperature at Complex Mold of (Activated Carbon/Polymer Binder)
}

\author{
Yong Gyun Lim***, Young Jun Kim*, Sang Jin Park** and Sung-Kyu Hong**,† \\ *MICROFILTER CO., LTD., Material R\&D Team, 162-1 Sansu-ri, Deoksan-myeon, Jincheon-gun, Chungbuk 365-842, Korea \\ **Department of Chemical \& Biochemical Engineering, Dongguk University-Seoul, 3 Pil-dong, Chung-gu, Seoul 100-715, Korea \\ (Received 11 October 2013; Received in revised form 23 December 2013; accepted 29 December 2013)
}

\section{요 약}

정수처리 방식에 있어서 소형화의 필요성이 증대됨에 따라 복합적인 기능을 갖는 단일구조 여과재 개발이 절실히 요구되고 있다. 본 연구에서는 단일구조를 가지는 필터개발을 위하여 활성탄과 고분자 바인더로 구성된 성형체를 압 출소결방식으로 제조하여, 제조된 성형체의 밀도, 공극률 및 유량을 평가하여, 최대유량을 가지는 성형체의 최적 압출 온도를 결정하였다. 또한 성형체의 공극률 평가에 있어서 전체 공극률뿐만 아니라 관통형 기공의 공극률을 추가로 평 가하여 유량과의 상관성을 평가하였다. 압출온도가 고분자 바인더의 Melting point인 $133{ }^{\circ} \mathrm{C}$ 이상인 $140 ~ 230{ }^{\circ} \mathrm{C}$ 에서 단일구조 복합 활성탄 성형체 구성이 가능하였으며, 압출온도 $170^{\circ} \mathrm{C}$ 가 복합성형체의 밀도가 낮고, 관통기공의 공극률이 높아, 최대유량을 가지는 복합성형체의 제조가 가능한 최적 압출온도로 확인되었다. 또한 복합성형체를 통해 흐르는 물의 유량은 성형체의 전체 공극률 보다 관통형기공의 공극률에 크게 의존함을 알 수 있었다.

\begin{abstract}
As the need for miniaturization in water purification filter increases, the development of filter media for single filtration with multiple function was strongly required. In this study, the molded activated carbon composed of single unit was manufactured by extrusion-sintering process, and then the flow rate, density and porosity were investigated using the molded activated carbon manufactured at various extrusion temperature. We confirmed that it was possible to manufacture the single unit-molded activated carbon when the extrusion temperature was $140 \sim 230{ }^{\circ} \mathrm{C}$ more than $133{ }^{\circ} \mathrm{C}$ being of polymer binder melting point, and the optimal extrusion temperature for the molded activated carbon with maximum flow rate was $170{ }^{\circ} \mathrm{C}$ since the molded activated carbon had low density and high through porosity. Also we confirmed that the flow rate through the molded activated carbon was strongly dependent upon through pore porosity compared to total porosity for the molded activated carbon.
\end{abstract}

Key words: Single Unit-molded Activated Carbon, Extrusion-sintering Process, Through Pore, Flow Rate

\section{1. 서 론}

정수처리 방식에 있어서 소형화의 필요성이 증대됨에 따라 단일 구조의 소형 정수처리 여과재개발이 절실히 요구되고 있다. 기존의

\footnotetext{
${ }^{\top}$ To whom correspondence should be addressed.

E-mail: hsk5457@dongguk.edu

†이 논문은 동국대학교 화공생물공학과 김병식 교수님(초당대학교 총장님)의 정년을 기념하여 투고되었습니다.

This is an Open-Access article distributed under the terms of the Creative Commons Attribution Non-Commercial License (http://creativecommons.org/licenses/bync/3.0) which permits unrestricted non-commercial use, distribution, and reproduction in any medium, provided the original work is properly cited.
}

소형 정수처리 방식은 일반적으로 서로 다른 4 5가지 여과재를 사 용한다. 즉, 침전필터, 활성탄필터, 멤브레인, 세라믹필터 등과 같이 복수개의 여과재를 사용하고 있다. 최근, 정수처리 여과재의 소형화 의 필요성이 증대됨에 따라 단일 여과재를 선호하게 되어 복합적인 기능을 갖는 단일 여과재의 개발이 필요하게 되었다.

단일 여과재는 복수의 여과재가 수행하던 역할을 동시에 수행해 야 한다. 즉, 일정이상의 유량을 확보하여야 하며, 물속에 포함된 입 자물질의 제거와 동시에 중금속(Heavy metal), 휘발성 유기화합물 (VOC) 등에 대한 흡착성능을 동시에 필요로 하게 된다. 이러한 다양 
한 기능을 하나의 여과재에서 구현하기 위하여 활성탄 성형체가 매 우 유용하며, 최근 사용이 빠르게 증가하고 있다 $[1,2,5,6]$

활성탄 성형체를 제작하는 방식으로는 여러 가지가 있지만, 경제 성이 우수한 방식으로는 금형압축소결방식(Hot pressing process)과 압출소결방식(Extrusion sintering process)이 있다. 특히, 압출-소결방 식은 연속생산이 가능하기 때문에 생산성과 균일성이 우수하나 초기 운전조건 설정의 어려움을 가지고 있다[3].

본 연구에서는 단일구조를 가지는 정수 필터개발을 위하여 활성 탄과 고분자 바인더로 구성된 성형체를 압출소결방식으로 제조하여, 제조된 성형체의 밀도, 공극률 및 유량을 평가하여, 최대유량을 가지 는 성형체의 최적 압출온도를 결정하였다. 또한 성형체의 전체기공 의 공극률과 관통형 기공의 공극률을 구분하여 측정하여, 유량과의 상관성을 평가하였다[4,5].

\section{2. 실 험}

\section{2-1. 실험재료}

압출소결방식으로 제조되는 복합 활성탄 성형체는 활성탄과 고분자 바인더로 구성된다. 본 연구에서 사용한 활성탄은 Table 1 의 특성을 갖는 Philippines PJAC社의 $80 \times 200 \mathrm{mesh}$ 를 사용하였고, 고분자 바 인더는 Table 2의 특성을 갖는 LG chemical의 LUTENE-H ME9180 $\mathrm{HDPE}$ 를 사용하였다.

\section{2-2. 재료의 입도분포}

활성탄과 고분자바인더의 입도분포는 PIDS(Polarization Intensity Differential Scattering)방식의 입도분석기 LS 13320(Beckman Coulter, USA)를 사용하여 평가하였다. Table 3의 입도분포를 보면 활성탄의 평균입도는 $164.2 \mu \mathrm{m}$ 이었으며, 바인더는 $231.6 \mu \mathrm{m}$, 활성탄/바인더 혼합분체의 평균입도는 $166.4 \mu \mathrm{m}$ 로 측정되었다.

Table 1. Physical properties of PJAC $80 \times 200$ mesh used as activated carbon

\begin{tabular}{lc}
\hline \hline Iodine Number & $1,224 \mathrm{mg} / \mathrm{g}$ \\
Bulk Density (Dry) & $0.483 \mathrm{~g} / \mathrm{ml}$ \\
Total Ash Content & $4.0 \%$ \\
\hline
\end{tabular}

Table 2. Physical properties of ME9180 used as polymer binder

\begin{tabular}{lc}
\hline \hline Melt Flow Index $\left(190^{\circ} \mathrm{C} / 2.16 \mathrm{~kg}\right)$ & $18 \mathrm{~g} / 10 \mathrm{~min}$ \\
Density $\left(23^{\circ} \mathrm{C}\right)$ & $0.958 \mathrm{~g} / \mathrm{ml}$ \\
Melt temperature & $133^{\circ} \mathrm{C}$ \\
Molecular Weight Distribution & Narrow \\
\hline
\end{tabular}

Table 3. Particle size distribution for activated carbon, polymer binder and mixture of activated carbon and polymer binder

\begin{tabular}{ccc}
\hline \hline & Mean : $164.2 \mu \mathrm{m}$ & $\mathrm{d}_{10}: 82.01 \mu \mathrm{m}$ \\
Activated Carbon & Median : $157.3 \mu \mathrm{m}$ & $\mathrm{d}_{50}: 157.3 \mu \mathrm{m}$ \\
& Mode : $168.9 \mu \mathrm{m}$ & $\mathrm{d}_{90}: 246.9 \mu \mathrm{m}$ \\
\hline \multirow{3}{*}{ Polymer Binder } & Mean : $231.6 \mu \mathrm{m}$ & $\mathrm{d}_{10}: 81.40 \mu \mathrm{m}$ \\
& Median : $203.5 \mu \mathrm{m}$ & $\mathrm{d}_{50}: 203.5 \mu \mathrm{m}$ \\
\hline \multirow{2}{*}{ AC : PB 83:17 } & Mede $: 223.4 \mu \mathrm{m}$ & $\mathrm{d}_{90}: 395.4 \mu \mathrm{m}$ \\
Mix & Median : $156.4 \mu \mathrm{m}$ & $\mathrm{d}_{10}: 92.52 \mu \mathrm{m}$ \\
& Mode $: 168.9 \mu \mathrm{m}$ & $\mathrm{d}_{50}: 156.7 \mu \mathrm{m}$ \\
\hline
\end{tabular}

Korean Chem. Eng. Res., Vol. 52, No. 2, April, 2014

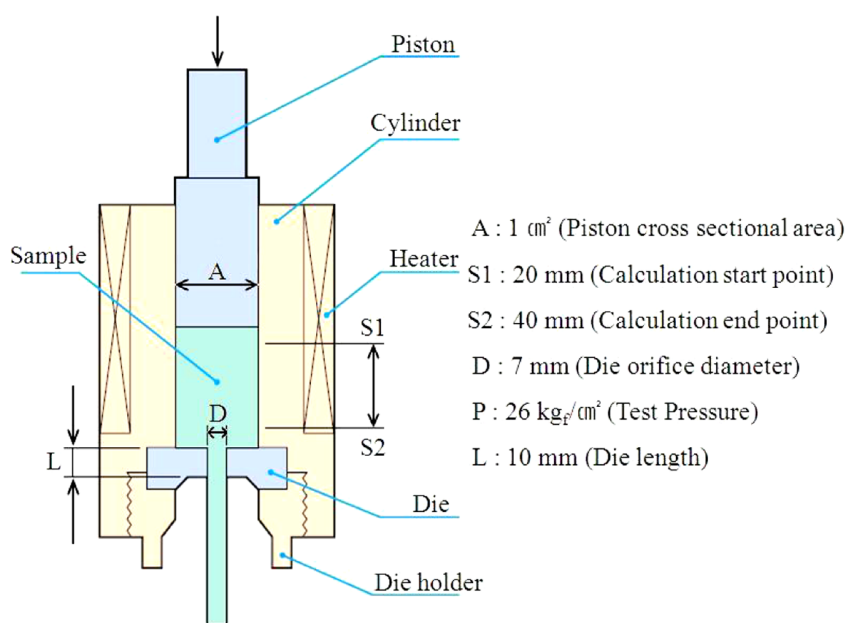

Fig. 1. Schematic diagram of extruder.

\section{2-3. 복합성형체의 제조}

복합성형체를 제작하기 위해사용한 압출기는 CFT-100D (SHIMADZU, Japan)를 개조하여 사용하였다. 압출온도를 균일하게 유지하기 위하 여 설정온도에서 600 초 동안 안정화시켰으며, 압출 피스톤의 압력은 $26 \mathrm{~kg}_{\mathrm{f}} / \mathrm{cm}^{2}$ 로 고정하였다. 압출기 다이헤드(Die head)에 해당되는 금 형부위는 토출구 $\phi 7 \mathrm{~mm}$ 금형으로 제작하여 결합하였다. 또한 압출 공정상 발생되는 마찰력을 감소시키기 위해 사용되는 $\operatorname{Wax}$ 등의 마 찰 감소제는 완성품의 용출특성에 영향을 줄 수 있기 때문에 사용하 지 않았다. 전체 실험장비에 대한 계략도는 Fig. 1에 나타내었다.

\section{2-4. 복합성형체의 공극률 분포 측정}

공극률 분포를 측정하기 위하여 수은압입법(Mercury intrusion porosimetry)을 이용하였으며, 측정기기는 AutoPoreIV(Micromeritics, USA)를 사용하였다. 수은압입법의 경우 여과제의 개방형기공(Open pore)과 관통기공(Through pore) 모두를 측정할 수 있기 때문에 유체 가 통과할 수 있는 관통기공만 구분하여 관찰하기 위하여 기포점 (Bubble point) 측정기를 통해 공극률을 비교하여 측정하였다. 기포 점 측정기는 Porometer $3 \mathrm{G}$ zh (Quantachrome, USA)를 사용하였다.

\section{2-5. 복합성형체의 유량측정}

복합성형체의 길이는 실증규모의 여과재로 사용되는 것의 평균 두 께인 $20 \mathrm{~mm}$ 로 적용하여 $\phi 7 \times 20 \mathrm{~mm}$ 의 원통형 여과재를 제작하였다. 유량측정 시 여과재를 우회(By pass)하는 현상을 방지하기 위하여 Fig. 2와 같이 유량측정 설비를 구성하였고, 길이방향으로 초순수를 통과시키며 압력별 유랑을 측정하였다.

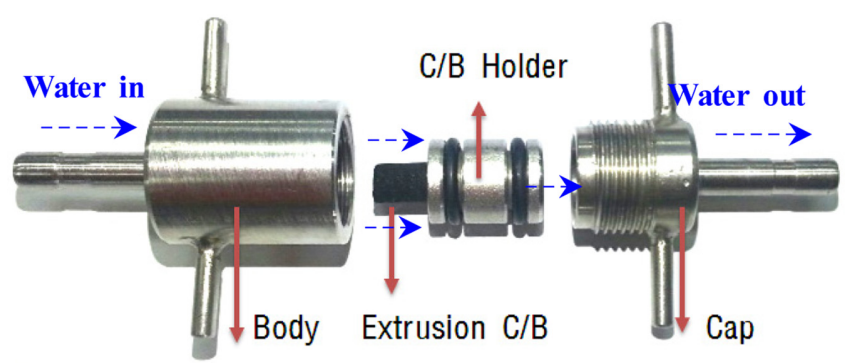

Fig. 2. Schematic diagram of test jig for measuring flow rate. 


\section{2-6. 복합성형체의 SEM관찰 및 $\mathrm{BET}$ 측정}

압출온도에 따른 복합성형체의 기공 분포와 표면특성을 분석하기 위하여 각각 $\mathrm{BET}$ 평가 및 $\mathrm{SEM}$ 관찰을 수행하였다. 바인더로 쓰인 고분자의 유동성으로 인하여 활성탄의 기공과 관통기공-이 막히는 현상을 확인하기 위해 $\mathrm{BET}$ 측정을 통해 비표면적을 확인하였다.

\section{3. 결과 및 고찰}

압출소결 장치로 복합 활성탄 성형체를 구성하였다. 고분자 바인 더의 Melting point인 $133{ }^{\circ} \mathrm{C}$ 이상의 온도에서 복합 활성탄 성형체를 구성할 수 있었으며, 압출온도에 따른 성형체의 점도, 밀도 및 유량을 측정하여 Table 4에 나타내었다. 실험은 압출 온도별 반복실험을 5 회 진행하여 평균값을 취하였다. Table 4로부터 압출온도 증가에 따 라 성형체의 점도는 낮아지고 용융지수(MFR)는 증가되었으며 밀도 역시 증가됨을 알 수 있었다.

활성탄 성형체 압출온도에 따른 전체기공율과 관통기공율의 변화를 Table 5에 나타내었다.

Fig. 3은 압출온도의 변화에 따른(활성탄/고분자바인더) 혼합물의 점도와 용융지수의 측정결과이다.

Fig. 3으로부터 압출 온도가 증가함에 따라 활성탄과 고분자 혼합 물의 점도는 낮아지고 압출속도는 증가함을 알 수 있었다. 따라서, 혼합물의 점도가 낮아지면 압출속도가 높아지고 압출 압력이 낮아져 성형체의 밀도가 감소할 것으로 예측된다.

Fig. 4는 압출온도의 변화에 따르는 성형체의 밀도를 측정한 결과 이다. Fig. 4로부터 성형체의 밀도가 압출온도 $160{ }^{\circ} \mathrm{C}$ 까지 감소하였 으나 이후 다시 증가하는 것을 알 수 있었다. 여기서, 압출온도 $140{ }^{\circ} \mathrm{C}$ 에서 $160{ }^{\circ} \mathrm{C}$ 사이의 성형체의 밀도 감소는 Fig. 3의 결과에 근 거하여 압출온도가 높아짐에 따라 용융지수가 증가함으로서 압출압 력이 감소하게 되어 성형체의 입자간 자유부피(Free volume)가 증가 되어, 최종 결과물로서 얻어지는 고체상의 성형체의 밀도가 감소되

Table 4. Physical properties according to the extrusion temperature

\begin{tabular}{ccccc}
\multicolumn{2}{c}{ change } \\
\hline \hline $\begin{array}{c}\text { Temp. } \\
\left({ }^{\circ} \mathrm{C}\right)\end{array}$ & $\begin{array}{c}\text { Melt flow rate } \\
(\mathrm{g} / \mathrm{min})\end{array}$ & $\begin{array}{c}\text { Viscosity } \\
(\mathrm{MPa} \cdot \mathrm{s})\end{array}$ & $\begin{array}{c}\text { Density } \\
(\mathrm{g} / \mathrm{ml})\end{array}$ & $\begin{array}{c}\text { Flow-rate }\left(\text { at } 0.5 \mathrm{~kg}_{\mathrm{f}}\right. \\
\left.\mathrm{cm}^{2}\right)(\mathrm{ml} / \mathrm{min})\end{array}$ \\
\hline 140 & 0.3511 & 5.5931 & 0.5994 & 32.07 \\
150 & 0.5056 & 2.6413 & 0.5969 & 33.15 \\
160 & 0.9315 & 0.7720 & 0.5767 & 39.47 \\
170 & 1.1526 & 0.5033 & 0.5852 & 39.37 \\
190 & 1.2597 & 0.4360 & 0.5845 & 39.98 \\
210 & 1.3964 & 0.3442 & 0.6020 & 39.67 \\
230 & 1.7998 & 0.2052 & 0.6213 & 38.60 \\
\hline
\end{tabular}

Table 5. Total pore porosity and through pore porosity according to extrusion temperature change

\begin{tabular}{ccc}
\hline \hline $\begin{array}{c}\text { Temp. } \\
\left({ }^{\circ} \mathrm{C}\right)\end{array}$ & $\begin{array}{c}\text { Total pore Porosity } \\
(\%)\end{array}$ & $\begin{array}{c}\text { Through pore porosity } \\
(\%)\end{array}$ \\
\hline 140 & 47.63 & 17.563 \\
150 & 47.66 & 18.298 \\
160 & 50.90 & 33.944 \\
170 & 49.41 & 33.082 \\
190 & 49.76 & 33.783 \\
210 & 48.18 & 32.154 \\
230 & 47.26 & 30.482 \\
\hline
\end{tabular}

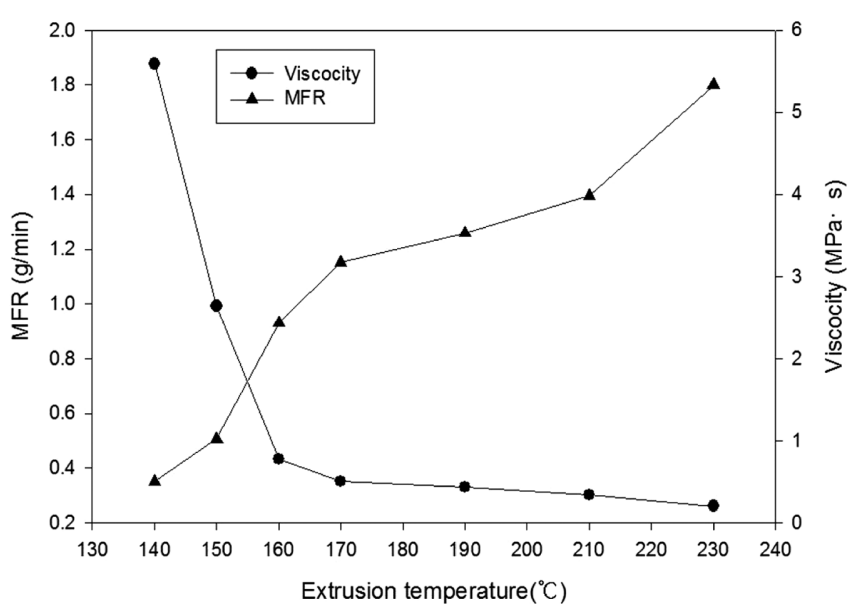

Fig. 3. Viscosity and MFR(Melt Flow Rate) as a function of extrusion temperature for mixture of activated carbon and polymer.

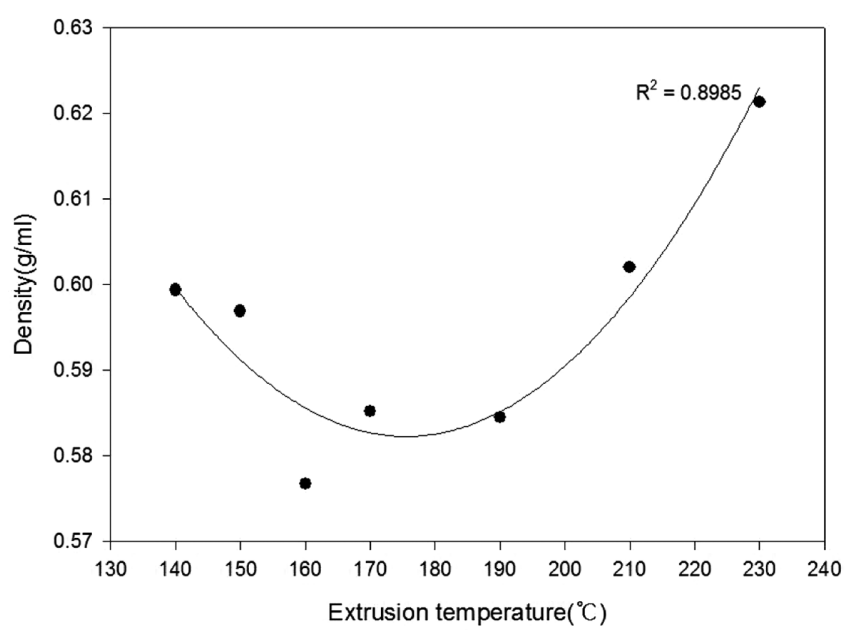

Fig. 4. Relationship between density and extrusion temperature for molded activate carbon.

었다고 판단된다. 반면 압출온도 $190{ }^{\circ} \mathrm{C}$ 이상에서 공극률의 감소와 밀도의 증가를 확인하였다. $190{ }^{\circ} \mathrm{C}$ 이상에서도 용융지수는 지속적으 로 감소하였기 때문에 압출압력의 증가에 따른 자유부피의 감소라고 할 수 없으며, 이는 고분자 바인더의 용융지수의 증가에 따른 자유 부피의 감소로 판단된다. 압출온도 $140 \sim 170{ }^{\circ} \mathrm{C}$ 사이에서 고분자 바 인더의 유동성이 낮아 압출 압력 증가에 따른 자유부피의 감소가 나 타나지만, $190^{\circ} \mathrm{C}$ 이상의 온도에서는 고분자 바인더의 유동성이 증 가하여 낮은 압력에서도 바인더가 활성탄 내부로 유동하여 성형체 내부의 자유부피를 감소시키는 것으로 판단된다.

Fig. 5는 압출온도의 변화에 따르는 압출성형체의 전체 공극률을 측정한 결과이다. 여기서 전체 공극률은 유로 중에 유체가 정체되는 개방형기공(Open pore)과 유로중에 유체가 통과되는 관통형기공 (Through pore) 비율을 합한 전체기공의 공극률을 의미한다. 즉, 성 형체의 비어있는 기공이 차지하는 모든 공간의 비율을 의미한다. Fig. 5 로부터 전체 공극률이 압출온도 $140{ }^{\circ} \mathrm{C}$ 에서 $170{ }^{\circ} \mathrm{C}$ 로 상승시 증가하다가 $190{ }^{\circ} \mathrm{C}$ 부터 다시 낮아지는 것을 확인하였다.

Fig. 4 와 5 를 동시에 검토한 결과 압출온도 $170{ }^{\circ} \mathrm{C}$ 에서 성형체의 밀도가 낮고, 공극율이 높은 성형체를 구성할 수 있는 것이 확인되 었다. 


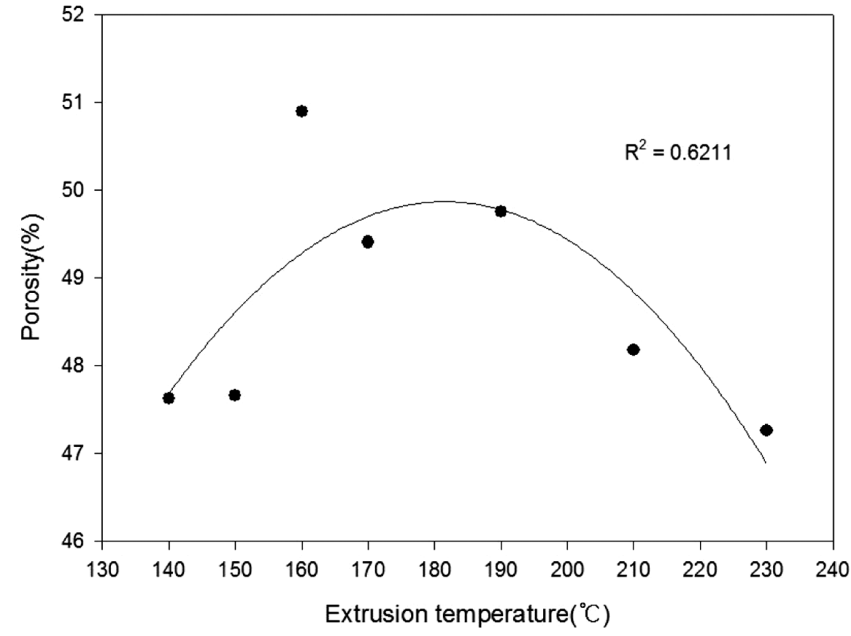

Fig. 5. Relationship between total pore porosity and extrusion temperature for molded activate carbon.

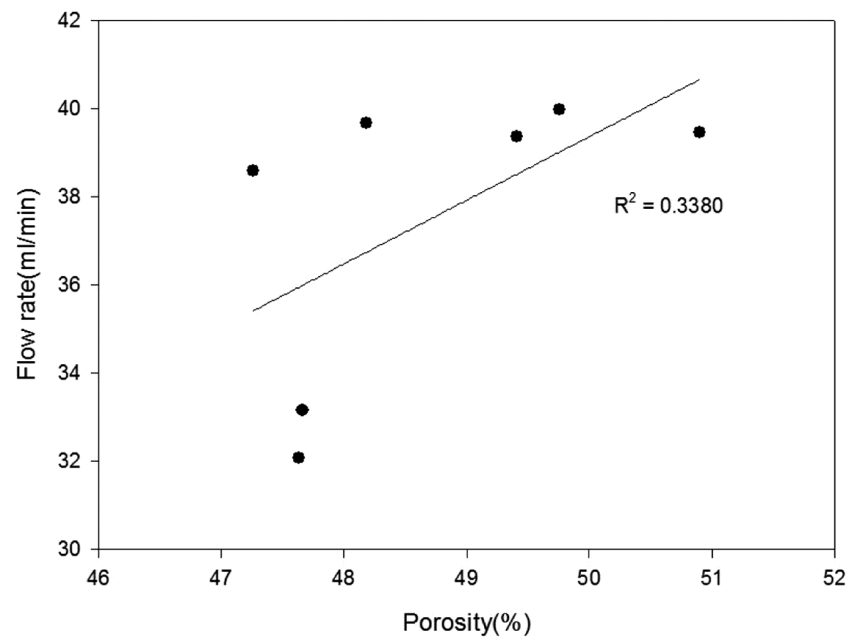

Fig. 6. Relationship between flow rate and total pore porosity for molded activate carbon.

Fig. 6은 유량과 성형체 전체 공극율의 상관성을 평가한 결과이다. Fig. 6 결과로부터 전체공극율과 유량의 상관계수가 $\mathrm{R}^{2}=0.3380$ 으로 약한 양의 상관관계를 가지는 것이 확인되었다. 이 결과는 활성탄 압 출 성형체에서 물은 관통기공을 통해서만 나갈 수 있기 때문에 개방 형기공과 관통형 기공을 모두 포함하는 전체 공극률이 유량과 약한 양의 상관관계를 나타내는 것을 의미한다. 따라서, 성형체의 공극률과 유량사이의 정확한 상관성을 평가하기 위해서는 유량과 직접적으로 관계되어 질 것으로 판단되는 관통형 기공의 공극률과 유량의 상관 성을 확인하는 것이 합리적이라고 판단된다.

Fig. 7은 성형체의 관통형기공의 공극률과 유량의 상관성을 평가 한 결과이다. Fig. 7 결과로부터 관통형기공의 공극률과 유량의 상관 계수가 $\mathrm{R}^{2}=0.9868$ 로 높은 상관관계를 갖는 것을 확인할 수 있었다. 즉, 이 결과는 활성탄과 고분자 바인더로 구성된 복합성형체에 있어서 통과 유량이 전체공극률보다는 관통형기공의 공극률에 크게 의존함 을 나타낸다.

Table 6은 압출온도에 따르는 성형체의 SEM 이미지와 BET 값 결 과이다. Table 6 에서의 SEM 사진을 통하여 압출온도 $170{ }^{\circ} \mathrm{C}$ 이상에

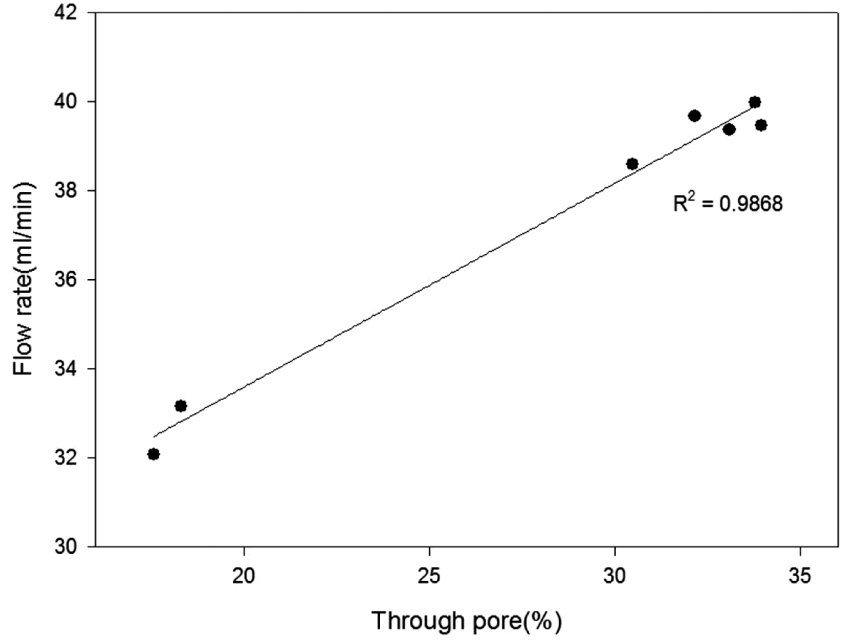

Fig. 7. Relationship between flow rate and through pore porosity for molded activated carbon.

Table 6. BET values and SEM images according to extrusion temperature change

\begin{tabular}{|c|c|c|}
\hline $\begin{array}{l}\text { Temp. } \\
\left({ }^{\circ} \mathrm{C}\right)\end{array}$ & $\begin{array}{c}\text { BET } \\
\left(\mathrm{m}^{2} / \mathrm{g}\right)\end{array}$ & SEM image \\
\hline 140 & 569.104 & \\
\hline 150 & 681.235 & \\
\hline 160 & 728.015 & \\
\hline 170 & 608.799 & \\
\hline 190 & 601.052 & \\
\hline 210 & 534.632 & \\
\hline 230 & 500.763 & \\
\hline
\end{tabular}


서 바인더가 활성탄을 감싸고 있는 모습을 볼 수 있었고, BET를 통 하여 압출온도가 $160{ }^{\circ} \mathrm{C}$ 를 정점으로 비표면적이 감소하는 경향을 확 인하였다. Table 6의 결과를 통하여 압출온도의 증가에 따라 성형체 의 용융지수가 증가됨에 따라 고분자 바인더의 유동성이 증가하여 고분자 바인더가 활성탄 성형체 사이의 공극을 채우고 있는 것을 알 수 있었다.

\section{4. 결 론}

활성탄과 고분자 바인더 혼합물을 이용하여 고분자 바인더의 Melting point인 $133^{\circ} \mathrm{C}$ 이상의 온도에서 압출소결방식으로 단일구 조의 복합 활성탄 성형체 제조가 가능하였다.

본 연구를 통하여 복합성형체의 압출온도가 $170{ }^{\circ} \mathrm{C}$ 일 때 밀도가 낮고, 관통기공의 공극률이 큰 성형체가 제조 가능한 것을 확인하였 다. 이를 통해 최대유량을 가지는 성형체를 제작 가능한 최적 압출 온도로서 $170{ }^{\circ} \mathrm{C}$ 가 확인되었다.

또한 복합 활성탄 성형체를 통해 흐르는 물의 유량은 성형체의 전 체 공극률 보다 관통형기공의 공극률에 크게 의존함을 알 수 있었다.

\section{감 사}

본 연구는 산업통상자원부의 지원으로 수행하는 부품소재개발사 업의 일환으로 수행되었습니다.

\section{References}

1. Moon, D.-C. and Lee, K.-H., "Micropore Analysis and Adsorption Characteristics of Activated Carbon Fibers,' Anal. Sci. Technol, 13(1), 89-95(2000).

2. Baek, Y.-M., Park, J.-C. and Kim, H.-J., “Adsorption Characteristics of Granular Activated Carbon Filter Used for Drinking Water Purifier,' J. Environ. Sci., 17(8), 899-905(2008).

3. Han, I.-S., Seo, D.-W., Hong, K.-S. and Woo, S.-K., "Effect of Forming Process and Particle Size on Properties of Porous Silicon Carbide Ceramic Candle Filters,' J. Resources Recycling, 19(5) 31-43(2010).

4. Lee, K.-H., Kim, S. Y. and Yoo, K.-P., "Evaluation of the Pore Size Distribution in Mercury Porosimetry Using Computer Simulations of Porous Media,' Korean J. Chem. Eng., 11(2), 131135(1994).

5. Asadullah, M. and Kabir, M. S., "Role of Microporosity and Surface Functionality of Activated Carbon in Methylene Blue Dye Removal from Water,' Korean J. Chem. Eng., 30(12), 22282234(2013).

6. Asadullah, M. and Jahan, I., "Preparation of Microporous Activated Carbon and Its Modification for Arsenic Removal from water,' J. Chem. Eng., Available online 1 (2013). 